\title{
Leaf dynamics and crop water status throughout the growing cycle of durum wheat crops grown in two contrasted water budget conditions
}

\author{
Nadine BRISSON*, Marie-Laure CASALS \\ Climate, Soil and Environment, INRA, Agroparc, 84914 Avignon Cedex 9, France
}

(Received 15 September 2003; accepted 15 November 2004)

\begin{abstract}
Leaf and crop water measurements were analysed dynamically throughout the cycle of two crops of durum wheat subjected to contrasting conditions of water supply. The objectives were to compare short- and long-term crop reactions to water deficit, based on some hypotheses from the literature. Water status measurements were of the first type and phenological or morphological measurements of the second type. The droughted crop under a rainout shelter received no water between emergence and harvest, while the open-air crop was irrigated. Dynamic plant morphological measurements consisted of leaf area index and specific leaf area, and those characterising plant water status dynamics included predawn leaf water potential, bulk osmotic potential and the ratio of crop water uptake to evaporative demand. Continuous measurement of the surface temperature on the two plots served to calculate a degree-days temperature scale, allowing comparison of the two crops. We found that the droughted crop developed mechanisms of resistance to water deficit: the leaf area index and specific leaf area were reduced (from 6 to $1.5 \mathrm{~m}^{2} \mathrm{~m}^{-2}$ and from 300 to $260 \mathrm{~cm}^{2} \mathrm{~g}^{-1}$ for the maximum values of, respectively, the LAI and the SLA), the bulk osmotic potential was lower (from -2 to $-3 \mathrm{MPa}$ ) and the soil layer affected by root uptake was deeper (from 50 to $100 \mathrm{~cm}$ ) than that of the irrigated crop. The amount of water evapo-transpired by both crops was similar when related to climatic demand. Yet no clear relationship appeared between the specific leaf area index and osmotic potential. Furthermore, there appeared to be a clear difference between the vegetative and reproductive phases of both crops in terms of water functioning. The osmotic potential decreased markedly after anthesis and a peak of water uptake was observed in both crops during the grain-filling phase, which may have been linked to the specific functioning of the flag leaf or the ear. While this study demonstrated the efficiency of drought adaptive features in durum wheat, it also showed that the difference in the water behaviours of two contrasted durum wheat crops could be of the same order of magnitude as the differences between the vegetative and reproductive phases.
\end{abstract}

durum wheat / phenology / specific leaf area / osmotic potential / leaf water potential / water uptake / early water stress

\section{INTRODUCTION}

When subjected to water deficit, plants develop both shortand long-term reactions which are seldom compared, although some evidence of a relationship between these two types of reactions exists in the literature, suggesting causal and not just empirical links.

Water deficit reduces the leaf area index of crops and this constitutes a type of adaptation to water shortage, allowing the plant to reduce its areas of gas exchange and consequently, its evaporative surface, thus inducing a reduction in stress through an improved balance between soil water availability and evaporative demand. The efficiency of this mechanism varies as a function of species; it is particularly marked in wheat [11] and sunflower [37]. The underlying processes are numerous: a slowing in cell multiplication and hence the production of new leaves, a reduction in cell expansion and an acceleration of senescence.

In most annual crops, a low leaf area index due to water deficit is associated with low specific leaf area values (ratio of leaf area to leaf mass). With respect to growth processes, it is known that leaf expansion is the first process to be affected by water deficit [7, 8], well before stomatal closure, which causes a reduction in specific leaf area [24]. Senescence processes bring about a remobilisation of carbon reserves from senescing to functional leaves [12], which also tends to reduce the specific leaf area.

Another response of plants to water deficit is a reduction in the osmotic potential, due either to the passive concentration of solutes resulting from dehydration, or to a net accumulation of solutes. The latter mechanism, also called osmotic adjustment, was demonstrated in wheat by Munns et al. [31] and Morgan et al. [29]. It is considered to be characteristic of drought tolerance [23]. Munns [30] suggested that osmotic adjustment might result from an increase in solutes, associated with a reduction in cell expansion. When comparing various species, Li et al. [24] demonstrated a relationship between specific leaf area and osmotic adjustment.

In addition to crop water status (and independent of it), the reproductive period of cereal crops has been shown to exhibit different water responses from the vegetative period. The presence of grains, the favoured carbon sinks after anthesis, changes the trophic relationships within the plant, which seems to have consequences for stomatal behaviour on the flag leaf $[6,14]$.

* Corresponding author: brisson@ avignon.inra.fr 
Table I. Mean values at $2 \mathrm{~m}$ of air temperature, radiation and potential evapotranspiration during the cycle (from emergence to harvest) of irrigated and droughted crops.

\begin{tabular}{lcc}
\hline & irrigated & droughted \\
\hline Tmin $\left({ }^{\circ} \mathrm{C}\right)$ & 10.6 & 10.1 \\
Tmax $\left({ }^{\circ} \mathrm{C}\right)$ & 21.6 & 24.3 \\
Global radiation $\left(\mathrm{MJ} \mathrm{m}^{-2} \mathrm{~d}^{-1}\right)$ & 19 & 14 \\
Potential evapotranspiration $\left(\mathrm{mm} \mathrm{d}^{-1}\right)$ & 4.5 & 3.9 \\
\hline
\end{tabular}

In durum wheat, the role of the ear as an organ for photosynthesis and transpiration [3, 1] can also cause differences between the vegetative and reproductive phases.

The aim of this study was to compare short- and long-term crop reactions to water deficit, based on the above-mentioned hypothesis from the literature. More specifically, a parallel analysis is proposed of leaf measurements (leaf area index, or LAI, specific leaf area, or SLA), determinations of water deficit (leaf water and bulk osmotic potentials) and water absorption dynamically throughout a cropping cycle under two contrasting conditions.

\section{MATERIALS AND METHODS}

\subsection{Experimental design}

Experiments were conducted at the INRA Research Centre in Avignon, France $\left(43^{\circ} 54^{\prime} \mathrm{N}, 4^{\circ} 48^{\prime} \mathrm{E}\right)$. Durum wheat $(c v$ Arcour) was sown on February 17, 1992 in a 0.4-ha field. At emergence, plant density was 180 plants $\mathrm{m}^{-2}$. The crop was cultivated under both dry and wet conditions. Drought was achieved by covering an $8 \mathrm{~m} \times 50 \mathrm{~m}$ area with a permanent PVC shelter throughout the growing cycle. This shelter excluded all water from the time of emergence until harvest, while the crop in the open air received $377 \mathrm{~mm}$ of water (rainfall + irrigation). As a secondary effect, the shelter induced a change in the crop microclimate, so that the two crops could not be considered as growing under the same climatic conditions (Tab. I): a reduction in levels of incoming radiation (around 25\%), midday air temperature higher and midnight air temperature lower than in the open air. The soil was a calcareous, loamy clay with a discontinuous stony band between 0.85 and $1.35 \mathrm{~m}$. Soil moisture reached $90 \%$ of field capacity $\left(0.31 \mathrm{~m}^{3} \mathrm{~m}^{-3}\right)$ at emergence. Complete nutrients, including $150 \mathrm{~kg} \mathrm{~N} \mathrm{ha}^{-1}$, were applied at sowing and then a further $50 \mathrm{~kg} \mathrm{~N} \mathrm{ha}^{-1}$ input was given to the wet crop during stem elongation. The previous crop on this plot had been a legume (soybean). In this paper, the crop under the rainout shelter will be referred to as the "droughted crop", and the crop in the open air as the "irrigated crop".

\subsection{Measurements}

The leaf area index (LAI) and specific leaf area (SLA) were determined by sampling every 2-4 days from the beginning of tillering until maturity, under both conditions. At each sampling, plants from a $0.5 \mathrm{~m}^{2}$ square were harvested, and a representative sub-sample of 5 wheat plants removed for SLA determination. The green leaves of both harvested samples $\left(0.5 \mathrm{~m}^{2}\right.$ and 5 plants $)$ were dried at $70^{\circ} \mathrm{C}$ for 3 days to determine the green leaf dry matter. The leaf areas of plants in the subsample were measured using a LICOR 3000 planimeter and the SLA was determined as the ratio of the area to the dry matter of the sub-sample leaves. The LAI was determined as the product of the green leaf dry matter of the total sample divided by the SLA of the sub-sample. At maturity, three sample areas of $0.25 \mathrm{~m}^{2}$ were harvested to determine the grain yield, final aboveground dry matter, and harvest index.

Predawn water potentials and bulk osmotic potentials were measured on the uppermost fully expanded leaf. Samples of 5 leaves from each treatment plot were harvested from the time of full soil cover (for the irrigated crop) until the beginning of flag leaf senescence. Water potential was measured using the pressure chamber technique on leaves inserted into a plastic bag after removal from the plant. After freezing and thawing, the bulk osmotic potentials were determined on the same leaves by thermocouple psychometry using a Wescor C-52 chamber. The bulk turgor potential was calculated as the difference between the water and bulk osmotic potentials.

The soil water content was automatically recorded by capacitive probes [17] connected to a Delta-T data logger. The probes were located at 10 depths in the soil from $0.05 \mathrm{~m}$ down to $1.20 \mathrm{~m}$. The in-situ gravimetric calibration of each probe was repeated 8 times throughout the experimental period, and supplemented by laboratory calibration in containers filled with the field soil. There was one site of measurement per plot but the calibration samples were collected at three locations in the plot. Field soil bulk density was measured for both plots by sampling cylinders of known volume. The precision of the water content measurements derived from the calibration data is about $0.02 \mathrm{~m}^{3} \mathrm{~m}^{-3}$. Mercury tensiometers were installed at depths of $1 \mathrm{~m}$ and $1.20 \mathrm{~m}$. Using these measurements we calculated for each treatment the depth of dried soil, as recommended by Gregory [18].

Climatic measurements for each section of the field included air temperature, vapour pressure, net and global radiation, radiative surface temperature, soil temperature at $0.02 \mathrm{~m}$ and wind speed, and were recorded automatically every ten minutes by the data logger. Most sensors were located at a height $0.80 \mathrm{~m}$ above the canopy; infrared thermometers were placed at $2 \mathrm{~m}$, which corresponds to a soil sighted area of $1.10 \mathrm{~m}^{2}$.

\subsection{Data processing}

\subsubsection{Logistic adjustments and tests on parameters}

In order to compare the dynamics of LAI and SLA values between different treatments, non-linear adjustments were based on the assumption that these dynamics could be expressed as the subtraction of two logistic curves (see Fig. 1):

$$
Y=Y 0+Y \max \left[\frac{1}{1+\exp (a 1(X-b 1))}-\frac{1}{1+\exp (a 2(X-b 2))}\right]
$$

$a 1, b 1, a 2, b 2, Y \max$ and $Y 0$ being the parameters to be estimated, $Y$ the LAI or SLA variable and $X$ a temporal variable, i.e. the sum of degree-days. To reduce the number of parameters to be estimated, we imposed the parameter $Y 0=170 \mathrm{~cm}^{2} \mathrm{~g}^{-1}$ for SLA and $Y 0=0$ for the LAI. Adjustments were made using 


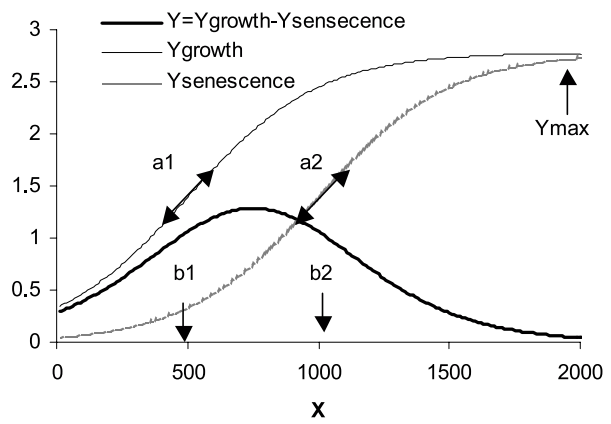

Figure 1. Illustration of the biological significance of parameters in the double-logistic

equation $Y=Y 0+Y \max \left[\frac{1}{1+\exp (a 1(X-b 1))}-\frac{1}{1+\exp (a 2(X-b 2))}\right]$ : $Y 0+Y \max$ is the value of the asymptote of both logistics (the former representing gross growth and the latter senescence), $(a 1, b 1)$ and $(a 2, b 2)$ are the slopes and the abscisses of the inflexion points of each logistic. In this example (parameters of Fig. 2b droughted crop) $Y 0=0$. and $Y \max$ are much higher than the maximum $Y$ value.

the Quasi-Newton method (Statistica $\bigodot$ StatSoft, Inc.), based on minimising the root mean square error. Each estimated parameter value was associated with a standard error, which made it possible to define a confidence interval around the central parameter value. Two curves were considered as being significantly different if the confidence intervals of at least one parameter were disjoint. If the intervals overlapped for all parameters, the curves could not be considered as being different. In the event of over-parameterisation, diagnosed by the software, the number of parameters was reduced by taking $a 1=$ $a 2$.

\subsubsection{Calculation of evapotranspiration potential}

The Penman-Monteith formula, as described by Perrier [33], was used to estimate the evaporative demand. Breakdown of the resistance to water vapour transfer into two terms (dependent upon convective air conditions and upon the crop) made it possible to account for the specific conditions induced by the shelter. Methods used for greenhouse climate management were applied to parameterising the coefficient for convection exchanges $\left(h_{c}\right)$ under the shelter and resulted in: $h_{c}=0.007+$ $0.0124 u_{2 m}$ where $u_{2 m}$ is the wind velocity at a height of $2 \mathrm{~m}$. For open-air conditions, we used the formula developed by Choisnel et al. [13]: $h_{c}=0.007+0.0056 u_{2 m}$. The canopy resistance of the reference crop was derived from lysimeter measurements and found to be equal to $60 \mathrm{~s} \mathrm{~m}^{-1}$ [13].

\subsubsection{Calculation of water uptake}

The daily soil water uptake was evaluated as the residue of the soil water balance within the investigated soil zone $(0.05-$ $1.20 \mathrm{~m})$. The tensiometers showed that neither drainage nor capillary rise occurred at the bottom of the soil profile. Runoff was not taken into account.
Table II. Agronomic characteristics summarising the growth, development and water functioning of irrigated and droughted crops from emergence to maturity.

\begin{tabular}{lcc}
\hline treatment & irrigated & droughted \\
\hline yield $\left(\mathrm{t} \mathrm{ha}^{-1}\right.$ ) & $4.38 \pm 0.27$ & $1.88 \pm 0.09$ \\
Harvest Index & 0.35 & 0.43 \\
Anthesis (days after sowing) & 102 & 85 \\
Physiological maturity (days after sowing) & 135 & 120 \\
Final dry matter $\left(\mathrm{t} \mathrm{ha}^{-1}\right.$ ) & $12.64 \pm 1.51$ & $4.36 \pm 0.65$ \\
Number of tillers per plant & $3.27 \pm 0.84$ & $2.01 \pm 0.70$ \\
Soil water uptake (mm) & 266 & 144 \\
Post-anthesis soil water uptake (proportion) & 0.63 & 0.65 \\
Cumulated potential evapotranspiration & 484 & 351 \\
until physiological maturity (mm) & & \\
$\begin{array}{l}\text { Depth of soil dessicated (cm) } \\
\text { Available water in the root zone (to } 1.2 \mathrm{~m} \text { ) }\end{array}$ & $337-267$ & $337-193$ \\
at emergence and at maturity (mm) & & \\
\hline
\end{tabular}

\section{RESULTS}

Table II, which summarises the agronomic behaviour of the two crops, demonstrated that anthesis in the droughted crop occurred 17 days earlier than in the open air. The structure of the plant population obtained differed because of a low rate of tillers combined with reduced leaf expansion in the droughted crop. The total biomass and grain yields were markedly higher in the irrigated crop. However, the harvest index for the droughted crop was $23 \%$ higher than that of the irrigated crop. Despite the absence of water input, the amount of water used was high in the droughted crop, representing $41 \%$ of the evaporative demand, which was not much less than the irrigated crop (55\%). This result could partly be explained by the soil depths explored by the two crops. It should be noted that the cumulative climatic demand under shelter resulted from microclimatic modifications induced by the presence of this shelter (Tab. I) and also from shortening of the cycle.

If air temperature was used to calculate phenological evolution, the droughted crop was characterised by a cycle reduced by 45 degree.days at the beginning of stem elongation and by more than 200 degree.days at anthesis. If temperatures closer to the thermal ambience of the plants were used (temperature at $2 \mathrm{~cm}$ in the soil or radiative temperature), the phenological evolution of the two crops tended to converge (Tab. III). Consequently, in the remainder of this paper, we shall refer to the sum of degree-days calculated using the radiative surface temperature as the time base, considering this as the basis in terms of physiological time or growing degree-days.

The difference in leaf growth was remarkable, with LAI peaks of about 2 for the droughted crop and 8 for the irrigated crop, and dynamics reflecting the shortening of the cycle (Fig. 2). This time difference disappeared when calculations were based on growing degree-days (Fig. 2b). Non-linear adjustment of LAI dynamics demonstrated that they were significantly different (Tab. IV). 
Table III. Growing degree-days above $0{ }^{\circ} \mathrm{C}$ calculated with three different temperatures and starting 13 days after emergence.

\begin{tabular}{lcccc}
\hline phenological stage & \multicolumn{2}{c}{$\begin{array}{c}\text { beginning of stem } \\
\text { elongation }\end{array}$} & anthesis \\
\hline treatment & irrigated & droughted & irrigated & droughted \\
\hline Air temperature & 464 & 419 & 1085 & 843 \\
Radiative temperature & 501 & 536 & 1074 & 1037 \\
Soil subsurface temperature & 463 & 507 & 1018 & 1019 \\
$(-2 \mathrm{~cm})$ & & & & \\
\hline
\end{tabular}
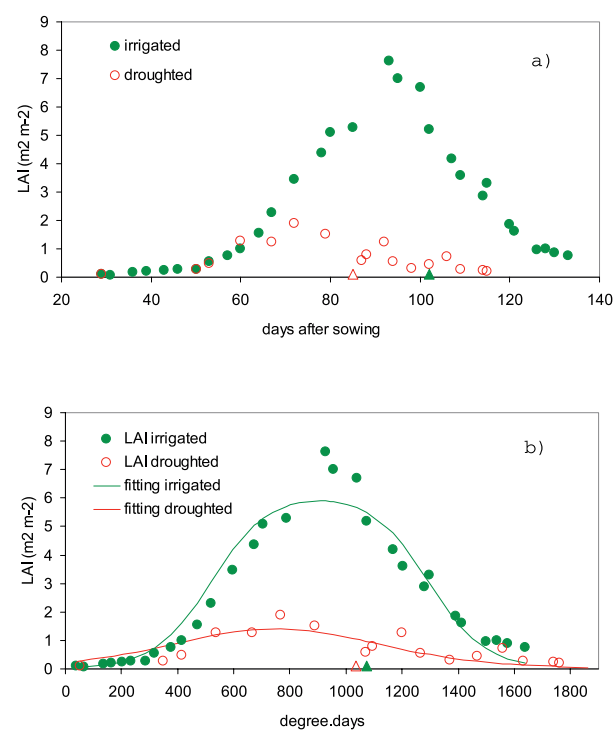

Figure 2. Leaf Area Index dynamics of the droughted and irrigated crops on (a) a calendar time basis and (b) a growing degree-days basis, calculated with the radiative surface temperature. The parameters of the fitting curves are given in Table IV. Arrows situate anthesis.

In both crops, SLA dynamics exhibited two successive increasing and decreasing phases. However, they differed significantly in terms of amplitude (maximum of around $250 \mathrm{~cm}^{2} \mathrm{~g}^{-1}$ in the droughted crop and $300 \mathrm{~cm}^{2} \mathrm{~g}^{-1}$ in the irrigated crop) and time delay (Fig. 3). Unlike the LAI, a delay was conserved when SLA dynamics were expressed in terms of degree-days (Fig. 3b). In the irrigated crop, SLA values increased until heading and remained roughly constant between heading and anthesis, while in the droughted crop the increasing phase seemed to stop at the beginning of stem elongation and the decreasing phase started before anthesis.

In both crops, the leaf water potential and its bulk turgor and osmotic components did not significantly evolve before anthesis (Figs. 4, 5). The average values before anthesis were $-0.6 \mathrm{MPa}$ and $-0.8 \mathrm{MPa}$ for leaf water potential, and $-1.0 \mathrm{MPa}$ and -1.2 MPa for bulk osmotic potential in the irrigated and droughted crops, respectively, and +0.4 $\mathrm{MPa}$ for bulk turgor in both crops. After anthesis, bulk osmotic potentials decreased while bulk turgor did not exhibit any significant evolution in either crops (Fig. 5), though a peak could be observed after anthesis. The leaf water potential remained relatively stable in the irrigated crop while it significantly decreased in the droughted crop.
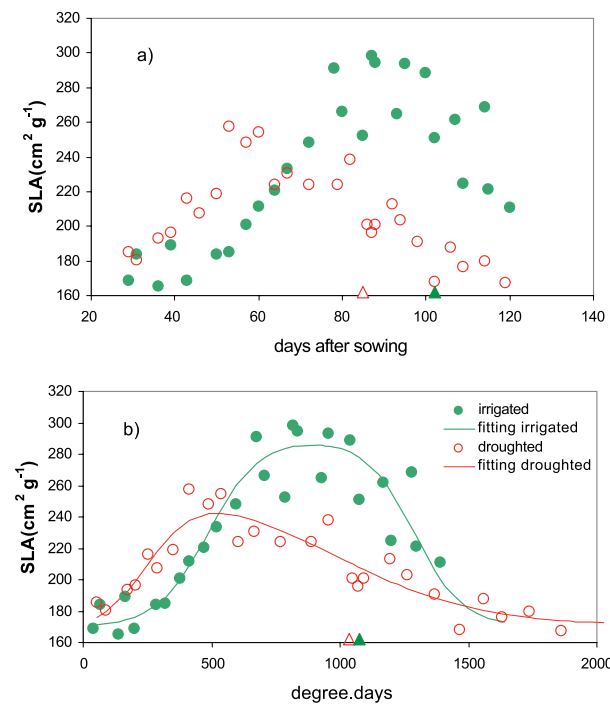

Figure 3. Specific Leaf Area dynamics of droughted and irrigated crops on (a) a calendar time basis and (b) a growing degree-days basis calculated with the radiative surface temperature. The parameters of the fitting curves are given in Table V. Arrows situate anthesis.

Table IV. Parameters of the fitted curves of LAI dynamics relative to growing degree-days. * Signifies that the resulting value is not significant at $P>0.95$, so that the two curves are statistically different $(P>$ $0.95)$.

\begin{tabular}{lcc}
\hline $\mathrm{X}=\mathrm{GDD}$ & \multicolumn{2}{c}{ LAI (Fig. 2b) } \\
\hline treatment & irrigated & droughted \\
Ymax & $6.16 \pm 0.44$ & $2.78 \pm 3.81^{*}$ \\
$a 1$ & $-0.010 \pm 0.001$ & $-0.004 \pm 0.001$ \\
$b 1$ & $520.6 \pm 28.2$ & $500.8 \pm 372.4^{*}$ \\
$a 2$ & $a 1$ & $a 1$ \\
$b 2$ & $1292.1 \pm 28.3$ & $999.7 \pm 339.0$ \\
\hline
\end{tabular}

Table V. Parameters of the fitting curves of SLA dynamics relative to growing degree-days. The two curves are statistically different $(P>$ $0.95)$.

\begin{tabular}{lcc}
\hline $\mathrm{X}=$ GDD & \multicolumn{2}{c}{ SLA (Fig. 3b) } \\
\hline treatment & irrigated & droughted \\
Ymax & $113.9 \pm 11.6$ & $93.6 \pm 30.0$ \\
$a 1$ & $-0.010 \pm 0.003$ & $-0.011 \pm 0.004$ \\
$b 1$ & $484.5 \pm 39.7$ & $250.4 \pm 28.6$ \\
$a 2$ & $-0.010 \pm 0.004$ & $-0.003 \pm 0.001$ \\
$b 2$ & $1289.7 \pm 41.4$ & $962.9 \pm 218.8$ \\
\hline
\end{tabular}

Figure 6 shows that no evident relationship could be seen between the bulk osmotic potential and SLA values, although after anthesis, SLA and bulk osmotic potential seemed to decrease simultaneously.

The relative water uptake dynamics (Fig. 7), i.e. the ratio of the actual water uptake to potential evapotranspiration, were quite similar in the two crops. In particular, it could be seen that 

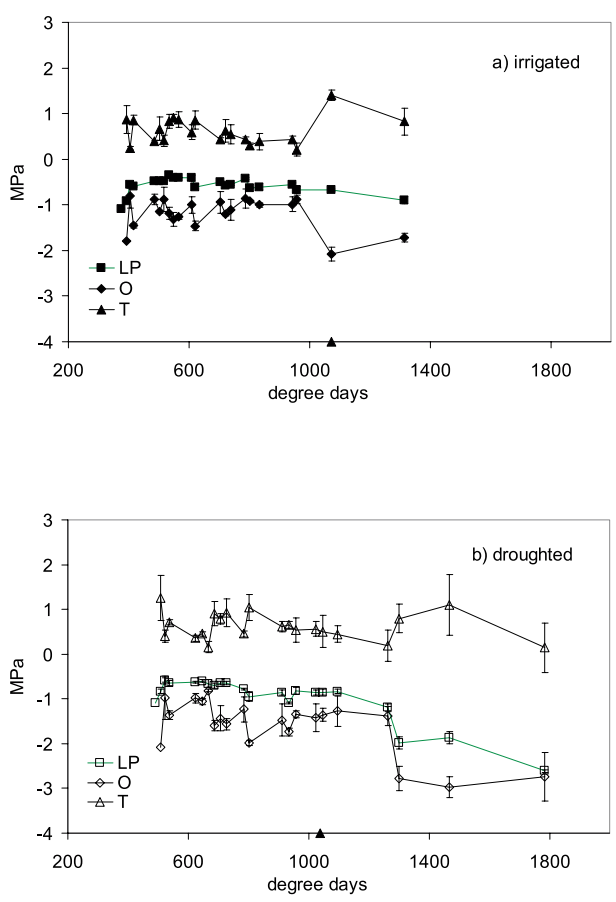

Figure 4. Evolution of leaf water potentials (LP) and their components, bulk turgor potential $(\mathrm{T})$ and bulk osmotic potential $(\mathrm{O})$ for irrigated (a) and droughted (b) crops. Arrows situate anthesis and standard deviations are given for each point.

even in the droughted crop, the ratio between uptake and evapotranspiration reached 1 . Two uptake peaks were observed in both crops: the first was concomitant with the increasing LAI phase and the second occurred later, when LAI was decreasing at the time when the ear had completely emerged. Anthesis occurred between these two peaks.

\section{DISCUSSION}

The dryness experienced by the droughted crop was early and essentially soil-related, as climatic demand was reduced under the shelter. This type of drought is known to favour the expression of mechanisms of drought adaptation [26, 41, 34, 21].

Of these mechanisms, drought escape, or the capacity of a plant to shorten its phenological cycle under dry conditions, has been demonstrated in wheat by several authors $[2,36]$. In line with the concept put forward by Idso et al. [22], the temperature prevailing for our crops provided an explanation for this mechanism, and its continuous recording in the two experimental areas served to calculate a scale of degree-days allowing comparison of the two crops.

Although we observed a marked difference in the foliage dynamics of the two crops, differences in their yields were less considerable, thanks in particular to a major increase in the harvest index. We had previously observed similar behaviour under different climatic conditions $[15,11]$, which were explained by Ludlow and Muchow [25] as being due to an important contribution by pre-anthesis assimilates to grain filling. Passioura [32] suggested that crops subjected to early
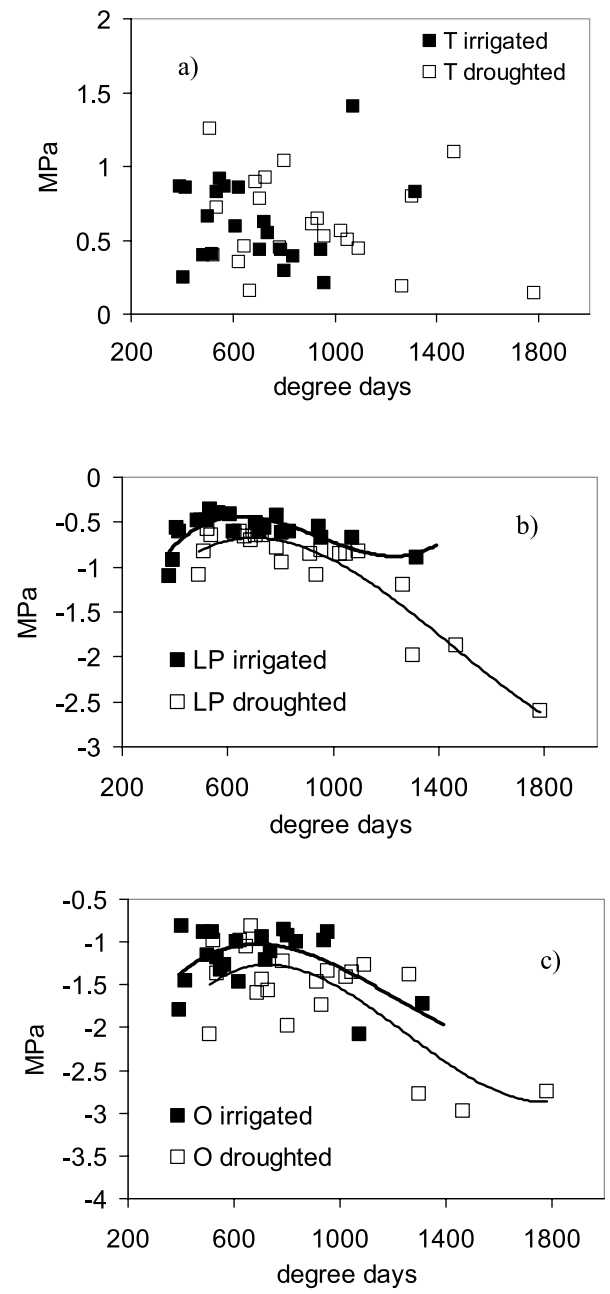

Figure 5. Treatment (irrigated in bold symbols and droughted in open symbols) and comparison of the potentials: (a) bulk turgor potential (T), (b) leaf potential (LP) and (c) bulk osmotic potential $(\mathrm{O})$. For LP and $\mathrm{O}$ polynomial fittings of degree 3 are given.

drought tend to save soil water during the vegetative phase, to the advantage of the grain-filling period. This may help to explain the phenomenon observed, particularly since the relative water uptake of the droughted crop was similar to that of the irrigated crop. As pointed out by Passioura [32], we also verified that $\mathrm{HI}$ increased with the contribution of post-anthesis to total water uptake (Tab. II).

In addition to this functional difference between the two treatments, our results demonstrated different water behaviours by crops in the vegetative and reproductive phases, whatever the treatment. The pre- and post-anthesis periods of SLA dynamics need to be analysed separately. Before anthesis, and even before heading, the foliage was growing and corresponded, together with stems, to the most important part of the carbon sinks. Thus, during this period, the measured SLA was the result of two processes: leaf expansion and carbon accumulation. At the beginning of the cycle, the increasing SLA was a sign that leaf expansion was more rapid than carbon accumulation. After anthesis, the leaves had stopped growing and 


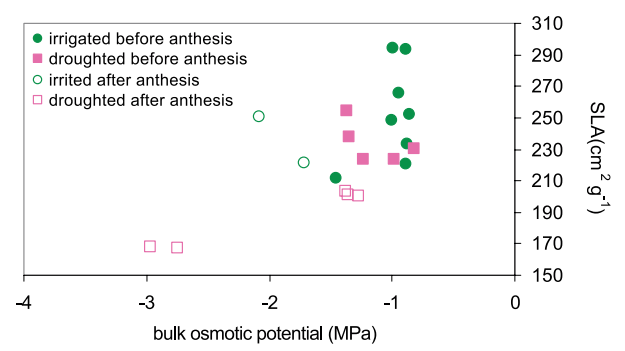

Figure 6. SLA as a function of osmotic potential and growth period for both treatments.
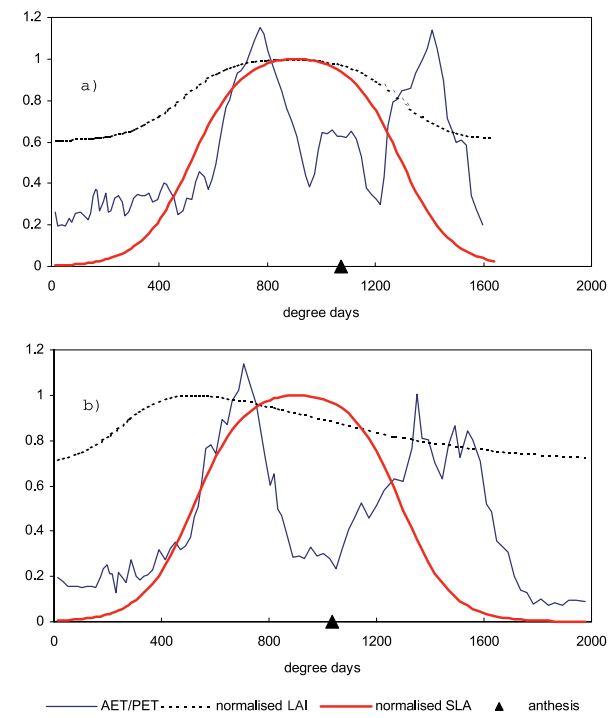

Figure 7. Comparison of three state variable dynamics: actual to potential evapotranspiration (AET/PET), normalised SLA (SLA/ $\max (\mathrm{SLA})$ ) and normalised LAI (LAI/max(LAI)) for (a) the irrigated crop and (b) the droughted crop. Arrows situate anthesis.

grains were the preferential sink: SLA evolution depended solely on carbon accumulation in green leaves (mainly flag leaves). This SLA plasticity is linked to the non-structural component of the leaf biomass [16], or, in other words, leaves seem to act as a reserve for assimilates when the sinks are not yet fully developed. In the droughted crop, this process occurred earlier during the vegetative phase because leaf expansion was limited due to water deficit. In that case, the sinks not yet fully developed were first leaves and then grains. In the case of plants subjected to water deficit, it is well known that the time elapsing between the halt in leaf growth and stomatal closure causes a reduction in specific leaf area [24]. Based on their study of several durum wheat genotypes, Simane et al. [38] demonstrated that the SLA was one of the factors best correlated with relative growth rate, while the leaf index was not at all correlated. As an application of these processes, in crop models the effect of water deficit on LAI dynamics often occurs via a relationship between the water deficit perceived by the roots and the SLA $[35,40]$. The difference in the LAI between the two crops was accompanied by a difference in the SLA, indicative of a major accumulation of biomass in the leaves of the droughted crop from the beginning of stem elongation. Unlike the irrigated crop, LAI and SLA dynamics were out of phase, thus confirming that the trophic equilibrium of the droughted crop differed from that seen in the irrigated crop.

Li et al. [24] observed a relationship between a reduction in SLA and that of the osmotic potential due to osmotic adjustment, showing that osmotic adjustment resulted from an imbalance between the production and consumption of photosynthates. These authors explained that this imbalance could be attributed to the delay between leaf growth and stomatal closure, and observed that this delay varied considerably between different grass species, or even between genotypes. They also demonstrated that it was directly correlated with osmotic adjustment. In their review articles, Blum [5], Munns [30] and Ludlow and Muchow [25] referred to the close relationship between osmotic adjustment and the reduction in plant growth observed by numerous authors. During our study, no relationship between SLA and osmotic potential could be seen during the growing phase. One reason could be that we did not measure osmotic adjustment, but just the decrease in bulk osmotic potential. Nevertheless, the parallel between water and osmotic potential dynamics during the vegetative phases suggested that the genotype under study exhibited a high capacity for osmotic adjustment [27], which corresponded to an increase in the concentration of intracellular solutes [39]. Another reason is that the cited studies concerned comparisons between genotypes and not comparisons between treatments throughout a growing cycle. That is to say, that growing processes can hinder or introduce noise in the assumed relationship between SLA in the growing phase and osmotic potential.

After anthesis, other mechanisms need to be invoked to explain the water behaviours of both crops: a steep decline in osmotic potential and a new phase of high water uptake during the senescence phase of foliage. The decrease in the osmotic potential of the flag leaf (the only leaf remaining green after anthesis) and the reduction in its SLA could be explained by its role as a reserve for grains. The reasons for the second peak of water uptake may be two-fold. Numerous authors have demonstrated that the water behaviour of the flag leaf is specific. Davidson and Chevalier [14] clearly showed an increase in wheat leaf conductance after heading. Furthermore, when investigating sink/source relationships in wheat, Blum et al. [6] assumed a possible relationship between the absence of reproductive sinks and low stomatal conductance under the influence of ABA. During a study of pearl millet, Henson and Mahlakshmi [20] found that stomata remained open once panicles had emerged. A second explanation is the role played by the ear and its beards as transpiration organs. We know that beards are endowed with stomata, and that in durum wheat, marked photosynthesis of the ear is an important source of assimilate for grains $[3,1]$. Based on radiative assessments, performed during the same trials, we were able to demonstrate [12] that the radiation intercepted by the ear was of the same order of magnitude as the interception of one LAI unit, whatever the conditions enjoyed by the plants.

Apart from dynamics, the global quantity of water evapotranspired by the droughted crop was very large and out of proportion with its LAI. In addition, because of the lack of water supply, we can assume that direct evaporation from the soil was low, unless capillary rises occurred within the soil depth explored by roots, providing the surface layer with water that could be 
evaporated. Based on the curve ranges seen in Figure 6, it was possible to conclude that the crop under shelter was not subjected to water deficit, as the plants used the same quantity of water as those in the open air. Thus, during our study, the leaf area index did not seem to have been a factor limiting transpiration. It is true that the sensitivity of stomata to water deficit is lower under conditions of weak evaporative demand [10]. In parallel, the roots of the droughted crop seem to have been particularly efficient, as testified by the depth of dessication, estimated as being double that seen in the irrigated crop. The relationship between osmotic adjustment and an increase in root extraction capacity was demonstrated by Morgan and Condon [28]. However, it seems unlikely that these results could be explained by increased water entry into the plant, resulting from a simple reduction in water potential [4]. Morphological adaptations due to the earliness of stress, concerning both shoots and roots, provide the most reliable explanations for this behaviour $[19,11]$. Based on anatomical observations, Zagdanska and Kozdoj [42] showed that the flag leaf of wheat subjected at an early stage to water deficit developed important adaptative characteristics, and notably an increase in stomatal density, allowing levels of photosynthesis comparable with those seen in a control crop.

\section{CONCLUSION}

While our study clearly demonstrated the efficiency of drought adaptive features in durum wheat, it also showed that the difference in water behaviours of two contrasted durum wheat crops could be of the same order of magnitude as the differences between the vegetative and reproductive phases. It is therefore important to compare crops at the same phenological stages. After anthesis, specific mechanisms occurred which were linked either to the role of the flag leaf or to the role of the ear. This would require specific experiments in the future because it appeared to be an efficient means of adaptation to drought. One way to demonstrate the generality of the droughtadaptive traits established during this study is to perform an integrative approach based on soil-plant modelling, which was indeed done by Brisson et al. [9] and Casals [12].

\section{REFERENCES}

[1] Abbad H., El Jaafari S., Bort J., Araus J.L., Comparison of flag leaf and ear photosynthesis with biomass and grain yield of durum wheat under various water conditions and genotypes, Agronomie 24 (2004) 19-28.

[2] Angus J.F., Moncur M.W., Water stress and phenology in wheat, Aust. J. Agr. Res. 28 (1977) 177-181.

[3] Araus J.L., Brown H.R., Febrero A., Bort J., Serret M.D., Ear photosynthesis, carbon isotope discrimination and the contribution of respiratory $\mathrm{CO}_{2}$ to differences in grain mass in durum wheat, Plant Cell Environ. 16 (1993) 383-392.

[4] Bittman S., Simpson G.M., Drought effects on water relations of three cultivated grasses, Crop Sci. 29 (1989) 992-999.

[5] Blum A., Crop responses to drought and the interpretation of adaptation, Plant Growth Regul. 20 (1996) 135-148.
[6] Blum A., Mayer J., Golan G., The effect of grain number per ear (sink size) on source activity and its water-relations in wheat, J. Exp. Bot. 39 (1988) 106-114.

[7] Boyer J.S., Leaf enlargement and metabolic rates in corn, soybean and sunflower at various leaf water potential, Plant Physiol. 46 (1970) 233-235.

[8] Bradford K.J., Hsiao T.C., Physiological responses to moderate water stress, in: Physiological Plant Ecology II, Springer Verlag (Ed.), Berlin, 1982, New Series 12B, Chap. 9, pp. 263-324.

[9] Brisson N., Casal M.L., Antonioletti R., Gate P., ARIBLE : un modèle dynamique de blé dur qui simule certains mécanismes de résistance à la sécheresse, Proceedings of the 16th ICID, Le Caire, 1996/09, 1, 1996, pp. 5-22.

[10] Brisson N., An analytical solution for the estimation of the critical soil water fraction for the water balance under growing crops, Hydrol. Earth Syst. Sci. 2 (1998) 221-231.

[11] Brisson N., Guevara E., Meira S., Maturano M., Coca G., Response of five wheat cultivars to early drought in the Pampas, Agronomie 21 (2001) 483-495.

[12] Casals M.L., Introduction des mécanismes de résistance à la sécheresse du Blé dur au fonctionnement phénologique et trophique de la plante dans un modèle dynamique de croissance, Thèse de doctorat INA-PG,1996, $130 \mathrm{p}$.

[13] Choisnel E., De Villèle O., Lacroze F., Une approche uniformisée du calcul de l'évaporation potentielle pour l'ensemble des pays de la Communauté Européenne. Office des publications officielles des Communautés Européennes (Ed.), Luxembourg, 1992, 178 p.

[14] Davidson D.J., Chevalier P.M., Storage and remobilization of water-soluble carbohydrates in stems of spring wheat, Crop Sci. 32 (1992) 186-190.

[15] Debaeke P., Puech J., Casals M.L., Élaboration du rendement du blé d'hiver en conditions de déficit hydrique. I. Étude en lysimètres, Agronomie 16 (1996) 3-23.

[16] Gary C., Jones J.W., Longuenesse J.J., Modelling daily changes in specific leaf area of tomato: the contribution of the leaf assimilate pool, Acta Hort. 328 (1993) 205-210.

[17] Gaudu J.C., Mathieu J.M., Fumanal J.C., Bruckler L., Chanzy A., Bertuzzi P., Stengel P., Guennelon R., Mesure de l'humidité des sols par une méthode capacitive : analyse des facteurs influençant la mesure, Agronomie 13 (1993) 57-73.

[18] Gregory P.J., Soil and plant factors affecting the estimation of water extraction by crops, in: Sivakumar M.V.K., Wallace J.S., Renard C., Giroud C. (Eds.), Soil water balance in the sudanosahelian zone, IAHS Publ. No. 199, 1991, pp. 261-273.

[19] Guichard S., Peut-on mettre on évidence un acclimatation à la sécheresse du fonctionnement hydrique du blé dur ? DEA Bases de la production végétale, Université de Montpellier, 1996, 15 p.

[20] Henson L.E., Mahalakshmi V., Evidence for panicle control of stomatal behaviour in water-stressed plants of pearl millet, Field Crop. Res. 11 (1995) 281-290.

[21] Huang B.R., Taylor H.M., McMichael B.L., Growth and development of seminal and crown roots of wheat seedlings as affected by temperature, Environ. Exp. Bot. 31 (1991) 471-477.

[22] Idso S.B., Jackson R.D., Reginato R.J., Extending the "degreeday" concept of plant phenological development to include water stress effects, Ecology 59 (1978) 431-433.

[23] Levitt J., Stress terminology, in: Adaptation of plants to water and high temperature stress, Turner N.C., Kramer P.J. (Eds.), Wiley, New York, 1980, pp. 437-439. 
[24] Li X., Feng Y., Boersma L., Comparison of osmotic adjustment responses to water and temperature stresses in spring wheat and sudangrass, Ann. Bot. 71 (1993) 303-310.

[25] Ludlow M.M., Muchow R.C., A critical evaluation of traits for improving crop yields in water-limited environments, Adv. Agron. 43 (1990) 107-153.

[26] Medrano H., Aguilo F., Socias F.X., Effect of drought on subterranean clover. 1. Leaf water relations of plants subjected to rapid or slowly induced drought, Photosynthetica 27 (1992) 413-419.

[27] Morgan J.M., Growth and yield of wheat lines with differing osmoregulative capacity at high soil water deficit in seasons of varying evaporative demand, Field Crop. Res. 40 (1995) 143-152.

[28] Morgan J.M., Condon A.G., Water use, grain yield and osmoregulation in wheat, Aust. J. Plant Physiol. 13 (1986) 523-532.

[29] Morgan J.M., Hare R.A., Fletcher R.J., Genetic variation in osmoregulation in bread and durum wheats and its relationship to grain yield in a range of field environments, Aust. J. Agr. Res. 37 (1986) 449-457.

[30] Munns R., Why measure osmotic adjustment? Aust. J. Plant Physiol. 15 (1988) 717-726

[31] Munns R., Brady C.J., Barlow E.W.R., Solute accumulation in the apex and leaves of wheat during water stress, Aust. J. Plant Physiol. 6 (1979) 379-389.

[32] Passioura J.B., Grain yield harvest index and water use of wheat, J. Aust. Inst. Agric. Sci. 43 (1977) 117-120.

[33] Perrier A., Étude physique de l'évapotranspiration dans les conditions naturelles. I. Évaporation et bilan d'énergie des surfaces, Ann. Agron. 26 (1975) 1-18.
[34] Plaut Z., Federman E., Acclimation of $\mathrm{CO}_{2}$ assimilation in cotton leaves to water stress and salinity, Plant Physiol. 97 (1991) 515522.

[35] Ritchie J.T., Otter S., Description and performance of CERESWheat a user-oriented wheat yield model USDA-ARS-SR Grassland Soil and Water Research Laboratory Temple RX, 1984, pp. $159-175$

[36] Robertson M.J., Giunta F., Responses of spring wheat exposed to pre-anthesis water stress, Aust. J. Agr. Res. 45 (1994) 19-35.

[37] Sadras V.O., Villalobos F.J., Fereres E., Wolfe D.W., Leaf Responses to Soil Water Deficits - Comparative Sensitivity of Leaf Expansion Rate and Leaf Conductance in Field-Grown Sunflower (Helianthus annuus L), Plant Soil 153 (1993) 189-194.

[38] Simane B., Peacock J.M., Struik P.C., Differences in developmental plasticity and growth rate among drought-resistant and susceptible cultivars of durum wheat (Triticum turgidum L. var. durum) Plant Soil 157 (1993) 155-166.

[39] Turner N.C., Jones M.M., Turgor maintenance by osmotic adjustment: a review and evaluation, in: Turner N.C., Kramer P.J. (Eds.), Adaptation of plants to water and high temperature stress, New York, John Viley and Sons, 1980, pp. 87-103.

[40] Weir A.H., Bragg P.L., Porter J.R., Rayner J.H., A winter wheat crop simulation model without water or nutrient limitations, J. Agr. Sci. Camb. 102 (1984) 371-382.

[41] Wilson J.R., Ludlow M.M., Fisher M.J., Shulze E.D., Adaptation to water stress of the leaf water relations of four tropical forage species, Aust. J. Plant Physiol. 7 (1980) 207-220.

[42] Zagdanska B., Kozdoj J., Water stress-induced changes in morphology and anatomy of flag leaf of spring wheat, Acta Soc. Bot. Pol. 63 (1994) 61-66. 